Review began 08/22/2021 Review ended 08/30/2021 Published 09/05/202

(c) Copyright 2021

Maqsood et al. This is an open access article distributed under the terms of the Creative Commons Attribution License CCBY 4.0., which permits unrestricted use, distribution, and reproduction in any medium, provided the original author and source are credited.

\section{Gender and Racial Trends Among Vascular Neurology Fellowship Programs: By Design or By Default}

\author{
Hamza Maqsood $^{1}$, Sadiq Naveed ${ }^{2}$, Shifa Younus ${ }^{1}$, Muhammad T. Khan ${ }^{3}$, Faisal Khosa ${ }^{4}$ \\ 1. Internal Medicine, Nishtar Medical University, Multan, PAK 2. Psychiatry, Hartford Hospital - Institute of Living, CT, \\ USA 3. Neurology, Charleston Area Medical Center, Charleston, USA 4. Radiology, Vancouver General Hospital, \\ Vancouver, CAN
}

Corresponding author: Shifa Younus, shifa.sheikh166@gmail.com

\section{Abstract}

\section{Introduction}

Benefits of increasing diversity in teams include the addition of different perspectives leading to increased innovation and creativity, faster problem solving, improved workforce morale, and reduced burnout leading to improved patient outcomes. This article reviewed the trend of gender and racial disparity in vascular neurology fellowship programs.

\section{Methods}

We retrospectively analyzed the data extracted from the Accreditation Council for Graduate Medical Education (ACGME)'s annual Data Resource Books from 2007 to 2019. ACGME cataloged gender as men and women and race/ethnicity was categorized as White/Non-Hispanic, Asian or Pacific Island, Hispanic, Black/Non-Hispanic, Native American/Alaskan, others, and unknown. Counts, proportions, relative, and absolute percentage changes were calculated to highlight trends in resident appointments over time and across the specialty of vascular neurology.

\section{Results}

The representation of females increased steadily; with a relative increase of $11.78 \%$ from the year 2007 to 2019. Race/ethnicity was reported starting from the year 2011. When averaged across the nine-year study period, $35 \%$ of the study sample was White (Non-Hispanic), followed by Asian/Pacific Islanders at $25 \%$. The representation of Hispanics was 4.8\%, Black/African Americans were 3\%, Native Americans/ Alaskans were $0.23 \%$ and Others were $13 \%$ of the total study population. For $17.7 \%$ of the fellows, racial data were not known and was categorized as Unknown racial distribution.

\section{Conclusion}

Our study concludes that gender and racial disparity persists within the fellowship programs of vascular neurology. Effective strategies at individual, administrative, and national levels are needed to engage women and under-represented minorities in vascular neurology as a career choice.

Categories: Medical Education, Neurology, Health Policy

Keywords: gender disparity, healthcare, vascular neurology, racial disparity, under-represented minorities

\section{Introduction}

Healthcare diversity is a fulcrum for raising healthcare standards, improving clinical outcomes, increasing patient satisfaction, and bringing innovation to society [1]. Healthcare needs are still catered by the homogenous care team, resulting in less-than-optimal care, clinical decision-making shortcomings, and poor financial outcomes in the pay-for-performance reimbursement model [2]. Despite changing social attitudes from assimilation models to valuing diversity, underrepresented minorities (URMs) face significant challenges. Existing literature has identified four underrepresented groups compared to their numbers in the general population: women, racial and ethnic minorities in medicine, sexual and gender minorities, and people with disabilities [3]. However, this problem is particularly concerning for the African American/Black and Hispanic/Latino minority groups, comprising $30.9 \%$ of the U.S. population compared to $9 \%$ of registered nurses and $8.5 \%$ of physicians from these racial minorities [4].

Diversity and inclusion of URMs raise optimism since women, African Americans, and Hispanics are more likely to serve the under-served populations [5-6]. The Liaison Committee of Medical Education (LCME) and Accreditation Council for Graduate Medical Education (ACGME) accreditation have focused on addressing gender and racial disparities in all facets. The Sullivan Commission report on diversity in the healthcare workforce has proposed three essential changes: change in the culture of health professions, new and non- 
traditional paths to healthcare, and commitment at leadership levels. These changes can become a catalyst for change and address current segregation and social exclusion [7].

Currently, the lack of diversity is evident across multiple subspecialties of medicine, NIH funding, professional societies, medical journal's editorial boards, and clinical trials [8-12]. Existing literature reflects several factors and their complex interplay that maintain and support this gender and racial disparity. Isolation, lack of camaraderie among current fellows, discrimination, communication barriers, greater debt burden, work-life imbalance, lack of mentorship, lack of females and minorities in programs, challenges in making meaningful relationships, and difficulties associated with obtaining grants are some of the factors contributing to gender and racial disparities, [13-14].

Gutierrez and colleagues analyzed the profile of medical school enrollees, graduates, and neurology faculty, suggesting significant disparities for the Black/African American and Hispanic/Latinos [15]. Men were 1.4 times more likely to attain higher education and become tenured than female counterparts [15]. This gap was more pronounced for leadership roles since only $12 \%$ of chairs were women and were White/Caucasian [15]. These findings were corroborated by another study exploring gender and racial trends among neurology faculty [16]. In another study eliciting these trends among neurology residents, no appreciable change was observed for underrepresented minorities [8]. The trends among neurology faculty and residents paint an almost similar picture for gender distribution, raising concerns among current efforts to eliminate disparities and their effectiveness. It provides insight into disparities among the neurology workforce; there is limited evidence exploring these trends in vascular neurology.

We investigated the gender distribution of fellowship trainees in vascular neurology over the 13 years from 2007 to 2019 and the racial distribution over nine years from 2011 to 2019.

\section{Materials And Methods \\ Data extraction}

Two team members (HM, SY) independently extracted the data from the Accreditation Council for Graduate Medical Education (ACGME)'s annual Data Resource Books. In this paper, we extracted the data for the fellowship trainees in the discipline of vascular neurology. The data for gender distribution are available from 2007 to 2019, whereas the data for races/ethnicity are available from 2011 to 2019. The data were extracted into Microsoft Excel sheets (Microsoft Corporation, Redmond, WA). The third team member (SN) reviewed the extracted data for accuracy and discussed any discrepancies. Race/ethnicity was categorized as White/Non-Hispanic, Asian/Pacific Islander, Hispanic, Black (Non-Hispanic), Native American/Alaskan, Others, and Unknown. Gender was reported as men, women, and Not Reported.

\section{Data analysis}

We analyzed the data by gender and racial distributions and its temporal trends by year among vascular neurology fellows using Statistical Package for the Social Sciences (SPSS), version 27 (IBM Corp., Armonk, $\mathrm{NY}$ ). Counts, proportions, and relative and absolute percentage changes were calculated to highlight trends in fellows appointments over time and across the discipline of vascular neurology.

\section{Ethical approval}

Ethical approval was not needed since there was no involvement of human or animal subjects. Our team sought all the information from the publicly available data of the ACGME.

\section{Results}

When averaged over the 13-year study period, $66 \%$ of all vascular neurology fellows were male, whereas the representation of females was 30\% (p<.001). Gender was not reported by $4 \%$ of the fellows. The representation of females increased steadily, with a relative increase of 15.18\% from 2007 to 2019. In 2007, males accounted for $70 \%$ while females accounted for $22.22 \%$ of all fellows in vascular neurology, whereas, in 2019 , males accounted for $64.5 \%$ while females accounted for $34.5 \%$ of all academic vascular neurologists (Figure 1). 


\section{Cureus}

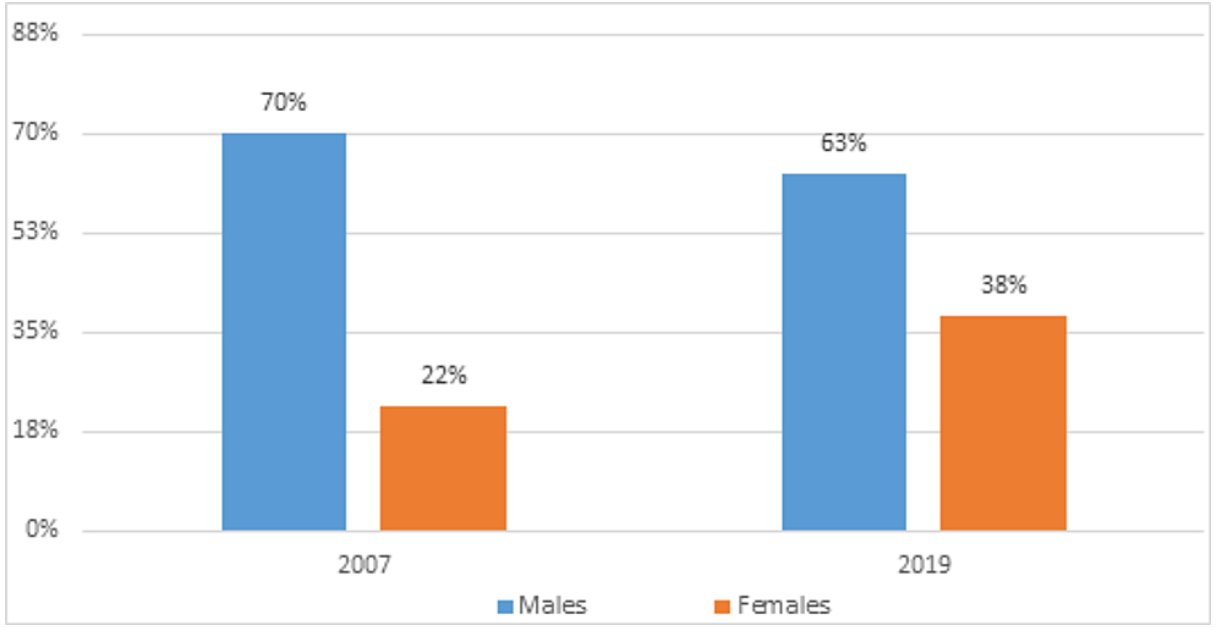

FIGURE 1: Gender differences at the beginning and end of our study period (i.e. 2007 to 2019)

For analysis of racial distribution, our study period ranged from 2011 to 2019. When averaged across the nine-year study period, $35 \%$ of the study sample was White (Non-Hispanic), followed by Asian/Pacific Islanders at 25\%. The representation of Hispanics was 4.8\%, Black/African Americans were 3\%, Native Americans/Alaskans were $0.23 \%$, and Others were $13 \%$ of the total study population. For $17.7 \%$ of the fellows, the racial data was unknown and categorized as Unknown racial distribution. The absolute change in racial distribution was highest for Asian/Pacific Islander (+20), followed by Whites (+18), Hispanics (+09), Black/African Americans (+2), Native Americans/Alaskans (00), and others (+3) (Table 1).

\begin{tabular}{|c|c|c|c|}
\hline & $2011(\%)$ & $2019(\%)$ & Absolute Change (\%) \\
\hline White & 36.3 & 36 & -0.3 \\
\hline Asian/Pacific Islander & 20.77 & 30.4 & +9.63 \\
\hline Hispanic & 00 & 7 & 07 \\
\hline Black/African Americans & 6.5 & 5.4 & -1.1 \\
\hline Native Americans/Alaskans & 00 & 00 & 00 \\
\hline Others & 14.28 & 11 & -3.28 \\
\hline \multirow[t]{2}{*}{ Unknown } & 20.77 & 11.7 & +9 \\
\hline & 2007 (\%) & 2019 (\%) & Absolute Change (\%) \\
\hline Males & 70 & 62. & -7.6 \\
\hline Females & 22.22 & 37. & 15.18 \\
\hline
\end{tabular}

TABLE 1: Gender and racial differences as well as absolute and relative changes at the start and end of our study period

The yearly percentage of all neurosurgery residents by race and gender is shown in Table 2 . 


\section{Cureus}

\begin{tabular}{|c|c|c|c|c|c|c|c|c|c|c|c|c|c|}
\hline & $\begin{array}{l}2007 \\
(\%)\end{array}$ & $\begin{array}{l}2008 \\
(\%)\end{array}$ & $\begin{array}{l}2009 \\
(\%)\end{array}$ & $\begin{array}{l}2010 \\
(\%)\end{array}$ & $\begin{array}{l}2011 \\
(\%)\end{array}$ & $\begin{array}{l}2012 \\
(\%)\end{array}$ & $\begin{array}{l}2013 \\
(\%)\end{array}$ & $\begin{array}{l}2014 \\
(\%)\end{array}$ & $\begin{array}{l}2015 \\
(\%)\end{array}$ & $\begin{array}{l}2016 \\
(\%)\end{array}$ & $\begin{array}{l}2017 \\
(\%)\end{array}$ & $\begin{array}{l}2018 \\
(\%)\end{array}$ & $\begin{array}{l}2019 \\
(\%)\end{array}$ \\
\hline White & & & & & 36.3 & 34 & 34.3 & 25.2 & 38.3 & 43.6 & 34 & 34.8 & 36 \\
\hline $\begin{array}{l}\text { Asian/Pacific } \\
\text { Islander }\end{array}$ & & & & & 20.7 & 23.4 & 26.1 & 28.5 & 33 & 17.4 & 34 & 21.7 & 30.4 \\
\hline Hispanic & & & & & 00 & 8.5 & 6.25 & 4.39 & 3.5 & 4.7 & 4.3 & 7 & 5.5 \\
\hline Black & & & & & 6.5 & 1.06 & 2.08 & 1.1 & 1.78 & 4 & 1.7 & 5.4 & 5.4 \\
\hline $\begin{array}{l}\text { Native } \\
\text { American/Alaskan }\end{array}$ & & & & & 00 & 00 & 00 & 1.1 & 00 & 0.8 & 00 & 00 & 00 \\
\hline Others & & & & & 14.2 & 9.4 & 13.5 & 18.7 & 10 & 20.6 & 9.5 & 9.3 & 11 \\
\hline Unknown & & & & & 20.7 & 22.3 & 17.7 & 21 & 13.4 & 8.73 & 16.5 & 21.7 & 11.7 \\
\hline Male & 70 & 62 & 62.2 & 65 & 66.2 & 56.3 & 71 & 74 & 58 & 67 & 69 & 64 & 62.5 \\
\hline Female & 22.2 & 26 & 28.7 & 27.6 & 23.7 & 42.5 & 27 & 26.3 & 42 & 33 & 30 & 34 & 37.5 \\
\hline Not Reported & 8.3 & 12 & 09 & 7.4 & 10.4 & 1.06 & 2.1 & 00 & 00 & 00 & 01 & 02 & 00 \\
\hline
\end{tabular}

TABLE 2: Temporal trends for race and gender and absolute percentage change from the year 2007 to 2019

\section{Discussion}

We investigated the gender distribution of fellowship trainees in vascular neurology over the 13 years from 2007 to 2019 and the racial distribution over nine years from 2011 to 2019. Despite an increase in the total number of fellowship positions in vascular neurology, significant racial and gender differences persist.

When averaged across the 13 years of the study period, almost $66 \%$ of all neurosurgery residents were men; these findings are consistent with previous studies, both for vascular neurology and other surgical specialties [17-19]. A study published in 2017 reported that vascular neurology, having been accredited for 11 years, had grown $860 \%$, averaging $78.18 \%$ more fellows each year. Despite an increase in fellowship positions, significant gender disparity exists, reported by only $26 \%$ of female residents in the study conducted by Williams et al. [20]. In our study, female trainees increased in proportion, and the absolute number of female trainees has also increased from $22.2 \%$ in 2007 to $34.5 \%$ in 2019 . These findings are consistent with existing studies suggesting a suboptimal increase in the percentage of female trainees in vascular neurology [20]. However, it is worth noting that the percentage of women entering into other neurology sub-specialties is encouraging [20-21].

Factors affecting choosing a fellowship have been examined extensively in the literature on various medical and surgical specialties. McNutt. et al. described some important factors for both men and women: friendly training environment, communication level among fellows, variety, number of cases, and the quality of relationships with the mentor [22]. Similarly, Auriemma and Whitehair conducted a study on trainees of physical medicine and rehabilitation and determined the highest-ranked factors including the perceived happiness of current trainees, opportunities for hands-on training, and perceived camaraderie [23]. These studies found that the female applicants preferred programs with a higher percentage of female faculty.

Isolation, lack of camaraderie among current fellows, duration and rigors of fellowship, lack of early discipline related exposure, relationship with the mentor, chances of placement in a fellowship, limited research opportunities, work-life balance, pregnancy, parental leaves, implicit bias, harassment, and lack of same-gender mentor due to the lackluster representation of females at higher academic tiers are some factors that can sustain gender disparity [20]. The underrepresentation of women in vascular neurology is more a consequence of discrepancies in opportunities, mentoring, or conscious or unconscious bias on residents and faculty [20]. Pregnancy and parental leave are among the most important issues for female vascular neurology trainees and practicing vascular neurologists and contribute to a smaller number of female fellowship applicants and higher attrition rates of female trainees and vascular neurologists [24].

A comprehensive plan to advance and support women's careers in vascular neurology should be devised at all levels. At the mentorship level, it should be determined if there may be bias in how female trainees are perceived or treated if there are differences in the way the mentors assess the capability of female trainees. For research and leadership initiatives, female trainees should be provided with the opportunity to lead 
projects that align with their interests [21]. At the institutional level, the strength of female mentors and career scientists should be increased to engage women in leadership positions and provide examples of success along with the provision and support of workshops, leadership seminars, and programs that address gender bias in research careers and academic promotion. Nominate women for awards that target specific challenges faced by women. An equal opportunity for participation and recognition in the discipline should be given [21]. At the national level, support should be provided for research for understanding antecedents and sustainers of gender bias. Opportunities should be provided for women's speakership and to incentivize the inclusion of female researchers in large collaborative science grants [21]. Acknowledging and publicizing the promotion of female vascular neurologists (especially those in senior leadership positions) could inspire, encourage, and motivate women in their early careers to aspire and prepare for leadership positions in the future [25].

A similar trend is seen while comparing the representation of different races within the fellowship programs of vascular neurology in the US. When averaged across an eight-year study period, the White/Caucasian race was over-represented in many years, but Asians led the racial trend among all vascular neurology fellows. There can be several explanations for our findings. A previous study has attributed the increasing Asian faculty representation to a parallel increase in the total population of Asians in the US [26]. Over the past two decades, the Asian population has been the fastest-growing racial or ethnic group and is projected to become the second-fastest-growing group from 2014 to 2060 [20]. The Black/African American, Hispanic, and mixed-race physicians have even less representation in healthcare. Although the strength of Asian/Pacific Islander faculty is growing steadily, they still face challenges increasing their representation in leadership positions. Several barriers are faced by under-represented minorities (URMs) in getting training spots and promotions in faculty positions, including a greater debt burden, limited communication skills, as well as racial prejudice and discrimination at the workplace [20,25]. The recruitment and retention of ethnic minorities are also affected by the lack of minority preceptors in vascular neurology [25].

In any area of societal evaluation, the causes of racial differences are complex and multi-dimensional, with discrimination being one of them. Structural/ Institutional racism is as important as individual discrimination [27]. Structural racism reflects a system in which public policies, institutional practices, and other norms perpetuate racial group inequality. Most physicians are not explicitly racist and treat patients on an equal basis. Structural racism is insidious, and various studies document disparate outcomes for different races despite individual health care professionals [28].

There is also a need for intensive and systematic educational campaigns to highlight racial disparities in health care. The awareness levels of the public and professional community, especially the medical community, must be raised. Research should be done to identify strategies that are most effective to raise awareness and increase sensitivity to racial discrimination in neurology in general and vascular neurology in particular [27]. Another critical goal of medical education should be to increase the number of minority professionals. But current trends show that these goals are unlikely to be achieved. There has been very little increase in the proportion of vascular neurologists' URM backgrounds in the last years. Finally, to provide clinical care and conduct research that contributes to equity, we believe it's crucial to "center at the margins." Centering at the margins signifies that we should re-anchor our academic and health care delivery systems- specifically, diversifying the workforce, developing community-driven programs and research, and helping to ensure that URM gains positions of leadership [13].

The findings of this study indicate that further research is needed into the multifactorial reasons contributing to the decreased representation of URM in fellowship programs in vascular neurology.

\section{Limitations}

Our study has its share of limitations. It focused on data on fellows of vascular neurology and thus may have limited generalizability to other sub-specialties. Our study utilized a dataset that describes gender in a binary fashion. Finally, our study did not explore the combined effects of being a gender and a racial minority such as female Hispanic or Black residents.

\section{Conclusions}

Our study concludes that gender and racial disparity persist within fellowship programs in vascular neurology. Efforts at all levels are needed to provide greater support for the females and for the careers of URM faculty to ensure their unbiased representation at all levels of academic neurology. Effective strategies at individual, institutional, and national levels can help increase the engagement of URM in choosing vascular neurology as their career.

\section{Additional Information \\ Disclosures}

Human subjects: All authors have confirmed that this study did not involve human participants or tissue. Animal subjects: All authors have confirmed that this study did not involve animal subjects or tissue. Conflicts of interest: In compliance with the ICMJE uniform disclosure form, all authors declare the 
following: Payment/services info: All authors have declared that no financial support was received from any organization for the submitted work. Financial relationships: All authors have declared that they have no financial relationships at present or within the previous three years with any organizations that might have an interest in the submitted work. Other relationships: All authors have declared that there are no other relationships or activities that could appear to have influenced the submitted work.

\section{References}

1. Chaudhary AM, Naveed S, Saboor S, Safdar B, Azeem MW, Khosa F: Gender and racial disparities among US psychiatry residents: a review of trends. Psychiatr Q. 2021, [Epub]: 10.1007/s11126-021-09888-W

2. Gomez LE, Bernet P: Diversity improves performance and outcomes. J Natl Med Assoc. 2019, 111:383-92. 10.1016/j.jnma.2019.01.006

3. Silver JK, Bean AC, Slocum C, et al.: Physician workforce disparities and patient care: a narrative review . Health Equity. 2019, 3:360-77. 10.1089/heq.2019.0040

4. Glazer G, Tobias B, Mentzel T: Increasing healthcare workforce diversity: urban universities as catalysts for change. J Prof Nurs. 2018, 34:239-44. 10.1016/j.profnurs.2017.11.009

5. Smedley BD, Stith AY, Colburn L, et al.: The Right Thing to Do, The Smart Thing to Do: Enhancing Diversity in the Health Professions: Summary of the Symposium on Diversity in Health Professions in Honor of Herbert W.Nickens, M.D. National Academies Press (US, Washington D.C; 2001.

6. Cantor JC, Miles EL, Baker LC, Barker DC: Physician service to the underserved: implications for affirmative action in medical education. Inquiry. 1996, 33:167-80.

7. Sullivan LW: Missing Persons: Minorities in the Health Professions, A Report of the Sullivan Commission on Diversity in the Healthcare Workforce. University of Maryland, Baltimore; 2004. 10.13016/cwij-acxl

8. Maqsood H, Naveed S, Mohyud Din Chaudhary A, Khan MT, Khosa F: Gender and racial trends among neurology residents: an overview. Postgrad Med J. 2021, [Epub ahead of print]: 10.1136/postgradmedj-2020139176

9. Chaudhary AM, Naveed S, Siddiqi J, Mahmood A, Khosa F: US Psychiatry Faculty: Academic Rank, Gender and Racial Profile. Acad Psychiatry. 2020, 44:260-6. 10.1007/s40596-020-01192-2

10. Zhang Y, Silver JK, Tiwana S, Verduzco-Gutierrez M, Siddiqi J, Khosa F: Physical medicine and rehabilitation faculty diversity trends by sex, race, and ethnicity, 2007 to 2018 in the United States. PM R. 2021, 13:994-1004. 10.1002/pmrj.12537

11. Ding J, Zhou Y, Khan MS, N. R, Khosa F: Representation of sex, race, and ethnicity in pivotal clinical trials for dermatological drugs. Int J Women's Dermatology. 2021, [In Press]: 10.1016/j.ijwd.2021.02.007

12. Hafeez DM, Waqas A, Majeed S, et al.: Gender distribution in psychiatry journals' editorial boards worldwide . Compr Psychiatry. 2019, 94:152119. 10.1016/j.comppsych.2019.152119

13. Hardeman RR, Medina EM, Kozhimannil KB: Structural racism and supporting Black lives - the role of health professionals. N Engl J Med. 2016, 375:2113-5. 10.1056/NEJMp1609535

14. Cohen JJ, Gabriel BA, Terrell C: The case for diversity in the health care workforce. Health Aff (Millwood). 2002, 21:90-102. 10.1377/hlthaff.21.5.90

15. Gutierrez C, Porter A, Ajiboye N, et al.: A snapshot of the Academic Neurology Workforce (1848) . Neurology. 2020, 94:

16. Saleem S, Naveed S, Mohyud Din Chaudhary A, Zeshan M, Hafeez D, Siddiqi J, Khosa F: Racial and gender disparities in neurology. Postgrad Med J. 2020, [Epub ahead of print]: 10.1136/postgradmedj-2020-138584

17. Leira EC, Kaskie B, Froehler MT, Adams HP Jr: The growing shortage of vascular neurologists in the era of health reform. Planning is brain!. Stroke. 2013, 44:822-7. 10.1161/STROKEAHA.111.000466

18. Capdeville M: Gender disparities in cardiovascular fellowship training among 3 specialties from 2007 to 2017. J Cardiothorac Vasc Anesth. 2019, 33:604-20. 10.1053/j.jvca.2018.10.030

19. Silver JK: Understanding and addressing gender equity for women in neurology . Neurology. 2019, 93:538-49. 10.1212/WNL.0000000000008022

20. Williams JSA, Hodgson TS, Goldenberg FD, Lukas RV: Trends in neurology fellowship training. Neurol Neuroimmunol. 2017, 4:65-68. 10.20517/2347-8659.2017.11

21. Minen MT, Law EF, Harriott A, Seng EK, Hranilovich J, Szperka CL, Wells RE: Challenges to successful research careers in neurology. How gender differences may play a role. Neurology. 2020, 95:349-59. 10.1212/WNL.0000000000010285

22. McNutt SE, Goss ML, Hallan DR, Bible JE: Factors in residency decision making for female neurosurgery applicants. World Neurosurg. 2020, 140:e105-11. 10.1016/j.wneu.2020.04.166

23. Auriemma MJ, Whitehair CL: How prospective physical medicine and rehabilitation trainees rank residency training programs. PM R. 2018, 10:286-92. 10.1016/j.pmrj.2017.08.445

24. Rangel EL, Smink DS, Castillo-Angeles M, Kwakye G, Changala M, Haider AH, Doherty GM: Pregnancy and motherhood during surgical training. JAMA Surg. 2018, 153:644-52. 10.1001/jamasurg.2018.0153

25. Palepu A, Carr PL, Friedman RH, Amos H, Ash AS, Moskowitz MA: Minority faculty and academic rank in medicine. JAMA. 1998, 280:767-71. 10.1001/jama.280.9.767

26. Lee D, Jalal S, Nasrullah M, Ding J, Sanelli P, Khosa F: Gender disparity in academic rank and productivity among public health physician faculty in North America. Cureus. 2020, 12 :e8553. 10.7759/cureus.8553

27. Williams DR, Rucker TD: Understanding and addressing racial disparities in health care. Health Care Financ Rev. 2000, 21:75-90.

28. Gee GC, Ford CL: Structural racism and health inequities. Old issues, new directions . Du Bois Rev. 2011, 8:115-32. 10.1017/S1742058X11000130 